meaningful. An independent person should do the marking or the questionnaire be sent to the College for analysis.

The questionnaires should be anonymous as the primary intention is to test the usefulness of educational meetings. This will propitiate the participation of professionals. Perhaps those who participate in completing the questionnaire may have a percentage refund as incentive in non local meetings that require a registration fee. For local (free) meetings local practitioners are most interested in making their own meetings useful so I assume that interest in participating will be tacitly present. Although not all meetings should be tested a reasonable number of different types of meetings should take part to permit useful generalisations.

The cooperation of College members is paramount to help obtain the necessary information about educational meetings. The majority of Sensky's sample favoured formal assessment of participation in $\mathrm{CME}$; therefore it seems that there exists an adequate background to support proposals which guarantee some form of objective measurement.

SENSKY, T. (1994) Continuing medical education: consultant psychiatrists' experiences and opinions. Psychiatric Bulletin, 18, 18-21.

DAVID MARCHEVSKY, Ealing Hospital, Southall, Middlesex UB1 3EU

\section{Defeat Depression Fun Run, 9 April 1895}

Sir: This event really was fun except that fewer than 20 psychiatrists took part. The majority of the 250 runners were patients, nurses, psychologists and paramedics.

The event had been well publicised and was generously sponsored by Smith, Kline \& Beecham who also provided drinks, chocolate for the exhausted, marquees and a grand timer clock. The considerable amount of work organising the event was undertaken by Chris
Gear and it was both disappointing and disloyal to the College that the psychiatric turnout was so meagre.

Could do better-next year, perhaps?

Sidney CRown, 14 Devonshire Place, London WIN IPB

\section{Medication levels}

Sir: As a schizophrenic patient who has been through the emergency provisions of the health service more than once and is now well integrated into an aftercare programme, I feel I have an angle on the provision of treatment which has not been adequately aired.

It is not difficult for somebody in my position to conclude that the medical profession is used in the psychiatric services as an arm of the state devoted to social control. We are forcibly given overdoses of medication to modify our behaviour such that the fears of carers concerning their perception of threat to ourselves or others are assuaged. In a Machiavellian sense this is understandable, although of considerable inconvenience to us sufferers.

There is another way: I have reached an understanding with my community psychiatric nurse such that I can experiment with the levels of dosage of Depixol which I take, with the result that we have found the minimum dose which works. The advantages of this are enormous; I get negligible side effects and have reached a state which can only be described as mellow. Accompanying this, I get creative, interesting and even fantastic dreams towards the end of the three weekly cycle of medication. The current practice of overkill in the provision of remedial chemicals would seem inappropriate for the needs of many patients.

My purpose in writing is to urge the psychiatric profession to consider more the quality of life of their patients and provide only such medication as will give them minimum abnormality combined with maximum creativity.

\section{Name and address supplied}

